\title{
Retailers, All Omni-Shoppers Are Not the Same
}

\author{
Nuria Viejo-Fernández ${ }^{\mathrm{a}, 1}$

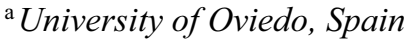

\begin{abstract}
Taking as a basis the elaboration likelihood model (ELM), this paper evaluates how the way in which the customer searches, evaluates and compares information influences the development of omni-channel behaviour, as well as each of its most common practices, webrooming (researching products online but purchasing products in a physical store) and showrooming (visiting physical stores to check out products and then buying them online). The results obtained from a sample of 939 apparel shoppers using the database constructed for the Spanish retail sector by GfK reflect that compared to one-stop shoppers, omni-shoppers (without distinguishing specific typologies) spend more time and effort planning their decision-making. The combination of physical and virtual channels makes it easier for the consumer to be more involved in the shopping experience and to search, compare and evaluate specific information about the product and/or retailer before the final purchase. This more reflective behaviour in which more time is spent on the consumer journey and more information is handled is what ELM defines as the central information processing route. While it is true that the central information processing route predominates, it is concluded when analysing each of the omni-channel behaviours separately that webroomers are more likely to follow this route, analysing in depth all issues related to the product they want to buy. On the other hand, although showrooming behaviour cannot be associated with the same intensity to the central information processing route, nor can it be associated with a less planned customer journey, like that of e-shoppers who focus only on prices and cost savings associated with the purchase. Showroomers use the internet to learn about retailer-related aspects as well as other consumers' opinions of the product before buying the product from the online store. Taking these results into account, managers should keep in mind the idea that webroomers and showroomers are as different as they are the same. Thus, both the internet and the physical store have to serve as both an information point and a shopping channel. Websites need to be usable and simple so that webroomers can get in-depth information about the retailer's portfolio and showroomers can make a purchase in a few quick steps. On the other hand, the physical store will be a touchpoint where omni-shoppers will enjoy unique experiences, highlighting the sales force that will be key for webroomers and showroomers to develop a stronger bond with the firm and not shop at any other competitor retailer.
\end{abstract}

Keywords. omni-channel behaviour, webrooming, showrooming, information processing routes

\section{Introduction}

Retail is currently a combination of offline and online channels. Academics and business practitioners agree [1] that one of the most relevant developments in the retail environment of recent decades is omni-channel retailing (OCR). In this sense, retailers

\footnotetext{
${ }^{1}$ Nuria Viejo-Fernández, Corresponding author: Department of Business Administration, Avenida del Cristo s/n, 33006 Oviedo, Spain; e-mail: nuriavjf@uniovi.es
} 
who want to survive in today's competitive markets will need this business model. OCR is defined as a strategy that integrates the online and offline touchpoints to create a seamless shopping experience that breaks down the barriers between virtual and physical stores and increases engagement during the customer journey $[2,3]$. Nowadays, the most common omni-channel behaviours are webrooming and showrooming. While webrooming begins with customers' product information-seeking behaviour through the internet followed by verifying the information by touching and feeling the products in the physical store, where the purchase is finalized, showrooming is the opposite practice [4]: this omni-channel behaviour starts in the physical store, where consumers gather information by 'touching and feeling' products, and ends with buying via the online channel [5].

Both of these behaviours pose a challenge for retailers. Therefore, it is necessary to analyse the drivers that explain what webroomers and showroomers are like so that organizations can segment and adapt their marketing strategies accordingly. The OCR literature from a consumer perspective started out very scarce, as most studies focused on analysing the effect of the combination of physical and virtual channels on companies' turnover, as well as other quantitative consequences of this behaviour. The positive reception of information and communication technologies (ICT) by shoppers without them leaving the physical store (but demanding new formats more suited to their current needs) influenced the OCR literature to focus more deeply on the analysis of consumer behaviour. Initially, demographic and sociocultural variables were the most widely used. However, depending on the product or sector analysed, the studies conducted did not obtain the expected results. These inconclusive results and the complexity that consumer journeys have reached [6] mean that the most recent research in OCR, in addition to the demographic and sociocultural profile, includes psychographic variables $[7,6,8]$. Psychographic factors are broad, and within them, psychological factors such as the self-concept, personality, lifestyle, motivations, interests, attitudes, opinions or values of the consumer, as well as the degree of involvement in the purchase, have significant weight. Involvement reflects the importance that the individual attaches to the specific attributes of the product he or she wishes to purchase, taking into account his or her interests and needs [9]. Therefore, models that analyse consumer behaviour can be taken into account to analyse involvement. Specifically, the elaboration likelihood model (ELM) will be used in this paper.

In this context, this research contributes to the OCR literature by focusing on the study of the effect of different forms of information processing. The results obtained will allow us to identify which type of information processing route is more likely to be associated with each of the omni-channel behaviours, webrooming and showrooming, versus one-stop shopping behaviours (pure offline and pure online).

\section{Literature review}

The ELM is one of the most widely used theories to study consumption habits. This model, developed by Petty and Cacioppo [10], shows that information processing during the customer journey can be explained by two factors: (1) the customer's motivation to search for information, and (2) the customer's ability to conduct an evaluation. Motivation is related to a customer's degree of involvement. Involvement is revealed as one of the most important variables in explaining and predicting consumer 
behaviour because of its influence on the processing of data stored in memory, on the external search for pre-purchase information, and on the formation of attitudes [11].

If customers are more involved with the purchase, their degree of motivation to seek and obtain information will be higher and will be accompanied by a greater investment of time and effort. Thus, information and messages will be analysed through the central route-i.e. in a more critical, rational and in-depth way, developing a proactive behaviour, seeking and paying greater attention to product-related information. In this sense, it is necessary that customers have prior knowledge about the topic or that they are able to connect such information with previous experiences [8, 12]. The alternative route proposed by Petty and Cacioppo [10] is the peripheral route. Customers who follow this route make less cognitive effort as they are less motivated and, consequently, develop lower levels of involvement. Likewise, they are characterized by having less capacity to process the information that allows them to make the purchase decision proactively.

Considering the characteristics of the central information processing route, it seems that it can be associated to a greater extent with the development of omnichannel behaviour. The reason is that omni-shoppers use the different touchpoints, physical and virtual, that organizations make available to them to search for information, compare and evaluate different proposals, and form an opinion on the product they want to buy and the retailer from which they want to make that purchase. Therefore, an omnishopper can be considered a "smart shopper" [8] since, as opposed to a one-stop shopper, whether pure offline or pure online, he/she combines offline and online channels in such a way that information or experiences that cannot be experienced in one channel can be made up for by using the alternative (for example, touching and feeling the products in the physical store). As a result, his/her customer journey is characterized by being more rational, reflective and longer. The proposed hypothesis is the following:

H1: A customer who follows the central route to information processing is positively associated with developing omni-channel behaviour.

However, this hypothesis can be qualified by analysing the two most recurrent omnichannel behaviours, webrooming and showrooming. According to ViejoFernández et al. [13], webroomers and showroomers have a different psychographic profile. This implies that the motivations that guide their consumer journey, as well as their levels of involvement, will be different despite the fact that both use offline and online touchpoints.

Webrooming behaviour seems to involve a more planned shopping behaviour compared to showrooming behaviour. In this sense, the webroomer uses the internet as a product specialist, gathering as much information as possible about different criteria related to the item he/she wants to buy (characteristics about the product, comparisons with other products...). Similarly, the online channel serves to examine the opinions of other customers and helps form an opinion that is not based on personal assessments or organizational information that may be biased, but on real experiences of other individuals. The information gathered on the internet means that the webroomer has a firm and decided idea about the product he/she wants to buy when he/she goes to the physical store. However, the salesroom plays an important role for these omni-shoppers, insofar as it is the touchpoint chosen to make the purchase of the product they wish to buy. According to Mckinsey and $\mathrm{PwC}[14,15]$, retailers need to provide a so-called "phygital experience" to engage customers. The phygital experience is about fostering a digital presence as well as the ability to buy online freely in store. Because webroomers 
are more involved in shopping and their leitmotiv is to seek as much information as possible to evaluate alternatives and make the right purchase decision, it is important for retailers to have tablets or other electronic devices available. By placing these technological tools as a part of the furniture at strategic points in the salesroom and/or next to the products, webroomers can expand the information as they see the product they want to purchase in the store (for example, prices in other competing retailers, characteristics of other similar products, need for accessories, colours, sizes...). The use of smartphones should also be allowed. Many retailers include frequency jammers in their shops, but far from making people buy, the opposite effect is achieved. In this sense, the smartphone will be used to help webroomers complete the information inside the store after seeing the products or listening to the salesperson [16]. The key is for retailers to be well positioned in the online channel.

Similarly, the salesperson is also key to closing the purchase. Webrooming consumers arrive with a firm idea of what they want to buy and with knowledge that can sometimes exceed the knowledge of salespeople, provided that the sales staff prolong the stay of these omni-shoppers in the physical store. The aim is to persuade them to change their opinion slightly (but not completely). Thus, retailing intelligence tools can help. For example, consumer recognition systems will help retailers to provide a personalized response according to the consumer's profile. To do this, retailers need to have a database of their shoppers in which their purchase history, average spending, etc. are collected. In this way, the salesperson, using a tablet, will be able to know the consumer's preferences and adapt to them, advising them in a way that the online channel cannot. Likewise, the salesperson can make use of commercial techniques such as cross-selling, which consists of offering the buyer a complementary product or accessories that complement the product they want to buy. They can also apply up-selling, which consists of suggesting to the buyer a product that will improve the initially chosen one: although it makes the purchase more expensive, the salesperson can argue that the higher outlay is worth it because it will exceed the customer's initial expectations.

Showroomers have a different psychographic profile to webroomers. While showroomers combine offline and online channels, they are e-shoppers. According to Solomon [17], two types of purchase motivation can be distinguished: utilitarian motivations and hedonistic motivations. Utilitarian motivations occur when consumers are oriented towards seeking functional or economic benefits. Hedonistic motivations are associated with the emotional component of the consumer, and the search for novel and pleasurable experiences during the purchase. If these motivations are applied to the omnichannel environment, the search for economic or functional benefits will be associated with the channel that saves on all the costs associated with shopping: time, effort, travel, price, etc. [18]. These features seem to characterize the online channel. Among the advantages of the internet as a shopping channel, reports analysing ecommerce reflect convenience, comfort or the availability of a varied product assortment at affordable prices. Therefore, since showroomers shop online, their motivations for purchasing the product will be utilitarian; consequently, since motivation and level of involvement are two closely linked psychographic variables, according to Rapp et al. and Yurova et al. [19, 20], showrooming consumers will have a lower level of involvement compared to webroomers. So, showroomers can be more easily persuaded by sales staff than webroomers, emphasizing the most attractive attributes of the brand or the physical store, which will be associated with utilitarian attributes. 
Regardless of the previous comments, showroomers are omni-shoppers. Therefore, showrooming consumers cannot be associated with either the peripheral route of information processing or the central route of information processing. They will be halfway between the two routes, for, although utilitarian motivations weigh a little more than hedonistic motivations, hedonistic motivations are latent. In this way, the experience lived in the physical store while informing will be important. Thus, enhancing sensory stimulation through the retailer's promotional activity, novelties, merchandising, or the availability of products in the shop, may positively influence these omni-shoppers to make the purchase in the retailer's virtual store [21,8], avoiding so-called competitive showrooming [22].

A comparison drawn between webrooming and showrooming leads us to make the following hypothesis:

$\mathbf{H}_{2}$ : Webroomers are more likely to use the central route to information processing than showroomers.

\section{Methodology}

To test the proposed hypotheses, the empirical research used the e-Commerce Observatory for the Spanish market conducted by GfK. Among the different retail sectors analysed in this database, this paper chooses the apparel sector because, in addition to its economic relevance for any developed country, it is also one of the sectors with the highest OCR index [23]. The GfK Spain database provides detailed information on the customer journey based on a sample of 939 customers who have purchased fashion products.

To measure the specific type of behaviour (omni-channel versus one-stop shopping), an endogenous multi-response variable (typebehaviour) with three mutually exclusive alternatives is used. Values 1 and 2 define individuals who follow an omnichannel behaviour, the first describing webroomers and the second showroomers. Value 3 includes all individuals who develop one-stop shopping behaviours (pure offline customers and pure online shoppers), this being the alternative chosen as a reference. In this case, the two types of one-stop shopper are not considered separately as the two individual samples are small (together they add up to 87 observations, 42 pure offline shoppers, 45 pure online shoppers). The smaller the sample, the more imprecision there will be in the results (and the wider the confidence intervals of the studied parameters). Thus, the differences will have to be larger in order to reach statistical significance. Thus, even if there is a real difference, its existence cannot be assured because the sample is too small, losing the opportunity to demonstrate differences that, although small, may be relevant.

To evaluate the information processing routes, the central route and the peripheral route proposed in the ELM, the research used three blocks of variables that were part of the GfK Spain database (Table 1). The first two blocks refer to the decision criteria related to the product and the retailer where the purchase is made, respectively. The third block of variables measures the degree to which a customer plans his or her purchase. All the items in these blocks are dichotomous variables. The value 1 refers to when the respondent has answered affirmatively to have carried out the action about which he/she is asked; the value 0 reflects the opposite. 
Table 1. Measurement of information processing

\begin{tabular}{|c|c|}
\hline Block & Code \\
\hline \multicolumn{2}{|c|}{$\begin{array}{l}\text { I. Determinant decision criteria relating to the product. "Regarding the product you purchased, what } \\
\text { information motivated you to make the purchase?" }\end{array}$} \\
\hline Price & priceproduct \\
\hline Characteristics & characteristicsproduct \\
\hline Comparisons with other products & comparativeproduct \\
\hline Reviews from customers & womcustomer \\
\hline \multicolumn{2}{|c|}{$\begin{array}{l}\text { II. Determinant decision criteria relating to the retailer. "Regarding the retailer from wh } \\
\text { purchase, could you state what information motivated you to make the purchase?" }\end{array}$} \\
\hline Product availability & availabilitystore \\
\hline Price & pricestore \\
\hline e-Commerce services & onlineservices \\
\hline \multicolumn{2}{|c|}{$\begin{array}{l}\text { III. Purchasing process. "Referring to the purchasing process, say which one of these sentences more } \\
\text { closely reflects your usual product purchases." }\end{array}$} \\
\hline I researched thoroughly and knew exactly what I wanted & thickinformation \\
\hline I spent time visiting shops and on shopping & thickcheck \\
\hline I went to the store only to buy the product & exclusivepurchase \\
\hline I had been thinking about buying the product for some time & musepurchase \\
\hline
\end{tabular}

Source: e-Commerce Observatory, GfK Spain

As proposed in the previous section, it can be assumed that those individuals who have followed the central route to information processing will analyse in great depth all the information related to the product they wish to purchase before making their acquisition. In this sense, they will not only analyse the characteristics, technical specifications or attributes, and the price in detail, but also those decision criteria related to a product that may be of greater relevance in determining their purchase (the possibility of making comparisons or the possibility of knowing the opinions of other consumers). Also, consumers who engage in such a proactive search for information will develop longer shopping journeys, where the buyers spend time and effort visiting different stores, comparing products and the information provided by the sales staff.

On the other hand, consumers who choose to follow the peripheral route to information processing are expected to focus their purchase decision on criteria related to the retailers selling the product and all the services they provide. As opposed to who have followed the central route to information processing the previous one, since they are not oriented to seek in-depth information about the products, their consumer journey will tend to be less prolonged and they will visit stores only with the objective of buying the article that is offered at the best price and/or at the retailer that they consider provides the best service.

\section{Results}

Table 2 shows the results of the estimated binomial logit model using statistical software STATA 12. The results show a good overall significance of the parameters and give some support to hypotheses $\mathbf{H}_{\mathbf{1}}$ and $\mathbf{H}_{\mathbf{2}}$ proposed in this paper. If one looks at 
the three blocks of variables used to measure information processing (central versus the peripheral route), there are a large number of significant results (highlighted in bold). In particular, 90 per cent of the items used have significant results that support the hypotheses posed. In this sense, when omni-channel behaviour is analysed without distinguishing between specific typologies $\left(\mathbf{H}_{\mathbf{1}}\right)$, it can be seen that omni-shoppers, compared to one-stop shoppers, have a longer decision-making period in which they invest time and effort in searching and evaluating the alternatives linked to the product they wish to acquire, as well as the characteristics linked to the retailer where they wish to make their purchase. Omni-shoppers analyse in depth all the characteristics related to the product they wish to buy, as well as the opinions of other consumers who have already bought the product, which in many cases serve to decide on the purchase (peerto-peer opinions currently carry more weight than one-way communication from companies). Similarly, omni-shoppers consider it relevant to obtain information on the price or availability of the product they want in retailers' physical and virtual shops. Moreover, in the case of omni-channel consumers who are e-shoppers, it is of vital importance to know what kind of online services firms provide in their e-commerce.

In summary, the results show that omni-shoppers (without distinguishing between specific typologies) follow the central information processing route. Therefore, their level of involvement in the purchase is higher than those consumers who only use a single channel (either offline or online).

However, when analysing the two most recurrent omnichannel behaviours, webrooming and showrooming, there are some differences that are worth pointing out. The results in Table 2 show that webroomers are more likely to be associated with the central information processing route than showroomers, as proposed in hypothesis $\mathbf{H}_{2}$. It seems that consumers who engage in webrooming behaviour inform themselves in depth prior to purchase, investing time in evaluating the different alternatives before making a firm decision and going to the physical store to buy. Thus, when analysing the block of variables relating to the product, we can see how vital it is for webroomers to search for information about the product they want to buy. All items are significant and positive (product price, characteristics, comparisons with other products, and opinions of other consumers). They also look for information on which retail outlets have availability of the goods they want and their prices.

Table 2. Binomial logit model estimated for webroomers and showroomers versus one-stop shoppers (pure offline and pure online customers)

\begin{tabular}{|c|c|c|}
\hline \multirow[b]{2}{*}{ Variable } & Webrooming & Showrooming \\
\hline & $\begin{array}{c}\text { Coefficient } \\
\text { (Robust Std. Err.) }\end{array}$ & $\begin{array}{c}\text { Coefficient } \\
\text { (Robust Std. Err.) }\end{array}$ \\
\hline \multicolumn{3}{|c|}{ Block I. Determinant decision criteria relating to the product } \\
\hline \multirow{2}{*}{ priceproduct } & $1.278^{* * *}$ & -0.158 \\
\hline & $(0.293)$ & $(0.301)$ \\
\hline \multirow{2}{*}{ characteristicsproduct } & $0.527 * * *$ & -0.300 \\
\hline & $(0.252)$ & $(0.351)$ \\
\hline \multirow{2}{*}{ comparativeproduct } & $0.483^{* *}$ & 0.109 \\
\hline & $(0.350)$ & $(0.462)$ \\
\hline \multirow{2}{*}{ womcustomer } & $0.785^{* *}$ & $0.702 *$ \\
\hline & $(0.361)$ & $(0.372)$ \\
\hline
\end{tabular}




\begin{tabular}{lcc} 
Block II. Determinant decision criteria relating to the retailer & $\mathbf{0 . 5 9 2 * *}$ \\
availabilitystore & $\mathbf{0 . 3 8 2 *}$ & $\mathbf{( 0 . 3 8 7 )}$ \\
& $\mathbf{( 0 . 1 7 8 )}$ & $\mathbf{0 . 4 5 2 * *}$ \\
pricestore & $\mathbf{0 . 4 9 6 * *}$ & $\mathbf{( 0 . 3 1 5 )}$ \\
& $\mathbf{( 0 . 2 0 1 )}$ & $\mathbf{1 . 2 0 1 * * *}$ \\
onlineservices & 0.901 & $\mathbf{( 0 . 5 5 5 )}$ \\
& $(0.274)$ & \\
Block III. Purchasing process & & 0.342 \\
thickinformation & $\mathbf{0 . 4 0 2 * *}$ & $(0.302)$ \\
thickcheck & $\mathbf{( 0 . 2 0 1 )}$ & 0.210 \\
& 0.198 & $(0.315)$ \\
exclusivepurchase & $(0.200)$ & $\mathbf{0 . 2 6 3} *$ \\
& 0.063 & $\mathbf{( 0 . 3 5 2 )}$ \\
musepurchase & $(0.199)$ & 0.122 \\
& $\mathbf{0 . 2 0 6 *}$ & $(0.296)$ \\
\hline
\end{tabular}

$* \mathrm{p}<0.10 ; * * \mathrm{p}<0.05 ; * * * \mathrm{p}<0.01$.

Showroomers, on the other hand, do not seem to have as long a purchase journey as webroomers. Therefore, it can be considered that their decision-making process is more impulsive. As shown in Table 2, showrooming consumers seem to visit only the online store of the retailer they are going to buy from. The retailer's information is important for these omni-shoppers, who look at the price the company sets for the product they want to buy, the availability of the merchandise in the company, and the online services the company provides. As far as product-related variables are concerned, the results obtained show that the opinions of other consumers are decisive when it comes to making a purchase, perhaps partly due to the low level of involvement in the search for information.

To complete the results in Table 2, a Chi-squared test is performed to analyse the differences between webroomers and showroomers (Table 3).

Table 3. Chi-squared test estimated for webroomers and showroomers versus one-stop shoppers (pure offline and pure online customers)

\begin{tabular}{lcccc}
\hline Variable & $\begin{array}{c}\text { Webrooming } \\
\mathbf{( 4 3 6 )}\end{array}$ & $\begin{array}{c}\text { Showrooming } \\
\mathbf{( 4 1 6 )}\end{array}$ & $\begin{array}{c}\text { One-stop shoppers } \\
\mathbf{( 8 7 )}\end{array}$ & Chi-squared \\
\hline Block I. Determinant decision criteria relating to the product & 322 & & \\
\hline \multirow{2}{*}{ priceproduct } & 315 & $(77.40 \%)$ & $(81.61 \%)$ & 19.36 \\
& $(72.25 \%)$ & 372 & 66 & $(\mathrm{p}=0.00)$ \\
characteristicsproduct & 408 & $(89.42)$ & $(75.86 \%)$ & 17.72 \\
& $(93.58 \%)$ & 304 & 48 & $(\mathrm{p}=0.00)$ \\
comparativeproduct & 386 & $(73.07 \%)$ & $(55.20 \%)$ & 6.61 \\
& $(88.53 \%)$ & 402 & 11 & $(\mathrm{p}=0.04)$ \\
womcustomer & 315 & $(99.01 \%)$ & $(12.65 \%)$ & 1.86 \\
& $(72.25 \%)$ & $(\mathrm{p}=0.07)$
\end{tabular}

Block II. Determinant decision criteria relating to the retailer 


\begin{tabular}{lcccc} 
availabilitystore & 387 & 396 & 48 & 22.58 \\
& $(88.76 \%)$ & $(95.19 \%)$ & $(55.17 \%)$ & $(\mathrm{p}=0.00)$ \\
pricestore & 403 & 411 & 13 & 12.76 \\
& $(92.43 \%)$ & $(98.80 \%)$ & $(14.94 \%)$ & $(\mathrm{p}=0.02)$ \\
onlineservices & 306 & 407 & 7 & 20.39 \\
& $(70.18 \%)$ & $(97.83 \%)$ & $(8.05 \%)$ & $(\mathrm{p}=0.00)$ \\
\hline Block III. Purchasing process & & & & \\
thickinformation & 387 & 315 & 9 & 7.75 \\
& $(88.76 \%)$ & $(75.72 \%)$ & $(10.35 \%)$ & $(\mathrm{p}=0.02)$ \\
thickcheck & 228 & 206 & 6 & 8.76 \\
& $(52.30 \%)$ & $(49.52 \%)$ & $(6.89 \%)$ & $(\mathrm{p}=0.09)$ \\
exclusivepurchase & 301 & 389 & 17 & 5.39 \\
& $(69.03 \%)$ & $(93.51 \%)$ & $(19.54 \%)$ & $(\mathrm{p}=0.07)$ \\
musepurchase & 367 & 360 & 22 & 15.37 \\
& $(84.17 \%)$ & $(86.54 \%)$ & $(25.28 \%)$ & $(\mathrm{p}=0.08)$ \\
\hline
\end{tabular}

\section{Discussion}

The objective of this research was to analyse how the way in which the customer searches, evaluates and compares information influences the development of omnichannel behaviour, as well as each of its most common practices, webrooming and showrooming. For this, the ELM was taken as a reference, whose postulate is to analyse the information processing routes, central route versus peripheral route.

This work has theoretical and managerial implications. In terms of theoretical implications, the results of this research support the findings of other similar studies (e.g. $[8,12])$ and contribute to the current state of the OCR literature. Omni-shoppers emerge as a category of shoppers who have a longer decision-making process than onestop shoppers. Combining channels and touchpoints, offline and online, implies a more reflexive behaviour that will be accompanied by a greater investment of time and effort. It is clear that this consumer can be defined as a "smart shopper", as he/she looks for information that can help him/her make the best decision and avoid the risk of making a mistake. Thus, information that cannot be found in the offline channel can be obtained from the online channel. Omni-shoppers will be informed in depth about all aspects related to the product in question, analysing its characteristics, the price range in which it sits, whether there is the possibility of complementing the product with accessories, and whether there are complementary products. They also use the comments and opinions of other buyers as a reference to make their decisions. As an omni-shopper, they will use traditional word of mouth (WOM) and e-WOM as a reference point. Peer-to-peer feedback is nowadays often more influential than advertising or retailer communications. In fact, according to López-López et al. [24], negative experiences are more resistant to change and those who experience them will want to communicate them with greater fervour to their peers as a way of getting back at the company. 
Similarly, it is important to find out about the retailer where the product is going to be purchased. Knowing the price set for the product that the consumer wishes to buy and the quantity of product available is relevant, above all, to avoid having to wait, or to wait as little time as possible for the item that he or she wishes to buy. This is especially relevant in the apparel sector, where some models, especially the most popular ones advertised by influencers, tend to sell out quickly. Omni-shoppers have increasingly complex consumer journeys [6], so many of them will have a greater affinity with ICT and will want to buy online. Thus, it is relevant for them to be informed about the services offered by e-commerce retailers. Knowing the delivery policy, shipping costs, or the possibility of making returns online and in the physical shop of the firm is something relevant for e-shoppers who are characterized by the fact that their purchase is guided by functional motivations.

While the above considerations are true, the omni-shopper is not a homogeneous consumer. The ways in which omni-shoppers combine offline and online touchpoints can be very varied: in fact, different nomenclatures have emerged in recent years to describe the most common types. However, academic literature and professional reports determine that the most recurrent omnichannel behaviours are webrooming and showrooming. According to Viejo-Fernández et al. [8, 12, 13], these omni-shoppers differ in their psychographic profiles, especially in the motivations that guide their purchase and, consequently, their involvement in it. The webroomer shows more planning behaviour and invests more time and effort in the search for and evaluation of information, especially related to the product he/she wishes to purchase. Although the webroomer is also informed about some issues related to the retailer (product availability and price), these issues are of vital importance for showroomers. Thus, as webroomers do not go to the salesroom with a definite idea of what they want to buy, being able to see the product, the price offered by the retailer and the services provided (especially online services) can decide the purchase. This implies that decision-making is more impulsive for showrooming customers.

The results obtained in this research help retailers to implement appropriate segmentation strategies to make OCR successful. Defining omni-shoppers as homogeneous consumers is wrong. In fact, the latest work on consumer behaviour and business practitioners is oriented towards analysing purchase journeys in order to try to give the appropriate response to each type of customer. This means that there is no uniformity in the way consumers search for and evaluate information, nor where they buy. The purchase journey may start offline and end online or vice versa, or it may start and end at the same physical (or online) touchpoint, using different virtual (or offline) touchpoints in between. While companies must be prepared for the complexity of the consumer journeys that are beginning to emerge, today they must focus on responding to two types of consumer in particular, webroomers and showroomers.

While webroomers emerge as individuals who develop a longer customer journey over time, looking for in-depth information about the product they want to buy, showroomers appear to be omni-shoppers with less planned purchasing behaviour. They look at the characteristics of the retailer-that is, showrooming consumers choose the company that offers the product at the best price with a certain level of quality. It can be considered that webroomers and showroomers are two sides of the same coin. Therefore, retailers' physical and virtual stores must be prepared to provide a seamless response to each of these two omni-shoppers insofar as they do not know a priori whether they will use the website or the physical store to search for information or to buy. 
Therefore, although the internet is linked to elements of a functional nature that are aimed solely at shoppers guided by utilitarian motivations such as saving time and effort, comfort or convenience, today's retailers must also promote elements that serve those omni-shoppers who have a greater involvement in the purchase and hedonistic motivations, such as webroomers. For these omni-channel consumers, the website where they look for product information is the first contact they have with the retailer. Therefore, the company's website should have a simple but eye-catching structure that is easy to navigate and use. It should also be accessible through any static or mobile device, the so-called responsive design. Colours should capture the user's attention without distracting them from what they want to look at. Images are essential so that the product can be seen in full detail. For this, the image needs to be enlarged and visible from different angles. It is also important that the virtual store has quality information about the portfolio of products that the firm sells, details of the price and main characteristics of the item in question, shows complementary products, whether it needs accessories, available stock, etc. The information should not be limited to the product: the services provided by the retailer, such as contact forms, delivery times, advice and personalized recommendations, opinions of experts and influencers, collection of shipping costs, flat rates or free shipping, are of great interest, especially for those consumers who buy online, such as showroomers. Likewise, the purchase process must be carried out in a few simple steps so that e-shoppers do not have a high abandonment rate.

For their part, physical stores must have a more up-to-date concept than they have had so far. This is what $\mathrm{PwC}$ [15] calls the phygital experience, which consists of incorporating ICT to achieve a strong bond with the shopper and, consequently, their engagement. According to Mosquera et al. and Viejo-Fernández [16, 25], the inclusion of tools such as tablets next to products, augmented reality, virtual fitting rooms or ibeacons can improve the shopping experience since information on the retailer's offer is available at all times. Retailers are interested in webroomers and showroomers staying as long as possible in the physical store - in the case of webroomers, who come to the salesroom with a firm idea and attitude towards what they want, to redirect them (without totally changing their mind) to buy a product more adapted to their needs which implies a higher outlay; and in the case of showrooming consumers, so that they can contemplate the advantages of buying the product from this firm, avoiding purchase in the online shop of a competing retailer or competitive showrooming [22]. For this reason, in addition to ICT, it is necessary that apparel retailers have a salesperson adapted to omni-shoppers. This is the so-called "salesperson 4.0" [26].

In addition to the traditional skills of a salesperson, such as empathy, listening skills and effective communication, it is necessary to add other skills that facilitate sales in the current environment where the weight of new technologies is so prominent. According to Gil [26], this salesperson must be an expert in digital marketing, given the hyperconnectivity of today's consumers, know the social media in which they find information before buying the product, and know what they are commenting on and what they prefer or reject. Knowledge management is also relevant, as having information about what the consumer thinks and wants allows the company to adapt its offer. The salesperson also needs to be creative, understanding creative as synonymous with resilience, and be able to adapt to the challenges of persuading today's consumers who, thanks to ICT, are increasingly informed about the characteristics of the product they want to buy and its price. Finally, the "talent 4.0" competence implies that the salesperson must seek excellence of results, which involves making sales so that retail 
companies meet their commercial objectives through the different physical and virtual channels they make available to consumers, preventing them from turning to the competition.

Finally, for showroomers characterized by a less planned decision-making process synonymous with a more impressionable behaviour, any element that activates their sensory stimulation should be promoted. Consequently, commercial strategies aimed at the showrooming consumer would involve the retailer encouraging the experience in the physical store and facilitating online shopping in store, encouraging salesperson 4.0 to take the initiative and show this omni-shopper in the physical store the products where the retailer is well positioned in terms of price so that showroomers can purchase them if they wish to do so in the virtual channel.

\subsection{Limitations and future research}

While the study has an extensive database for empirical research, it has two important limitations. On the one hand, the e-Commerce Observatory is a cross-sectional study that focuses on a specific time period. On the other hand, despite the fact that the database was created by an expert company, GfK Spain, not all the variables it incorporates are in line with what it is intended to measure.

It should be noted that the research has focused on a specific sector, apparel retailing. Also, the study has basically focused on the two most common types of omnichannel behaviour, webrooming and showrooming. However, it is possible to identify more specific behaviours, such as click and collect or drive-through, that have not been contemplated in this study. Future research could aim to consider these omni-channel behaviours. Understanding which specific touchpoints, offline and online, the customers use at each stage of the purchase, why they make use of those touchpoints and not others, and how they behave at each stage would further advance the OCR literature.

It would also be of great value to study the factors that condition omnichannel behaviour, especially those related to psychographic variables, as well as the consequences from a cognitive-affective perspective, since, although there are studies that analyse these variables, they are still scarce and incipient, both separately and jointly. Finally, future research could include other retail sectors in order to verify whether the results follow a pattern. In this sense, it would be particularly interesting to consider omnichannel behaviour in the case of sectors where OCR has a low index, such as the toy sector.

\section{References}

[1] World Retail Congress (2020). Omni-Channel Retailing: The new normal. Available at: https://www.worldretailcongress.com/partner-content/omni-channel-retailing-the-new-normal.

[2] Grewal, D., Motyka, S., Levy, M. The Evolution and Future of Retailing and Retailing Education. Journal of Marketing Education. 2018; 40(1): 85-93.

[3] Flavián, C., Gurrea, R., Orús, C. Combining channels to make smart purchases: The role of webrooming and showrooming. Journal of Retailing and Consumer Services. 2020; 52: 101923.

[4] Aw, E.C.X., Basha, N.K., Ng, S.I., Ho, J.A. Searching online and buying offline: Understanding the role of channel-, consumer-, and product-related factors in determining webrooming intention. Journal of Retailing and Consumer Services. 2021; 58: 102328.

[5] Fiestas, J.C., Tuzovic, S. Mobile-assisted showroomers: Understanding their purchase journey and personalities. Journal of Retailing and Consumer Services, 2021; 58: 102280. 
[6] Radzevičè, J., Banytè, J. Driving Factors of consumer irrationality in Omnichannel Consumer Behaviour. Marketing and Smart Technologies, Singapore: Springer; 2020.

[7] Nakano, S., Kondo, F.N. Customer segmentation with purchase channels and media touchpoints using single source panel data. Journal of Retailing and Consumer Services. 2018: 41: 142-152.

[8] Viejo-Fernández, N., Sanzo-Pérez, M.J., Vázquez-Casielles, R. Webroomers versus showroomers: Are they the same?. Journal of Business Research. 2018; 92: 300-320.

[9] Drichoutis, A.C., Lazaridis, P., Nayga, R.M. An assessment of product class involvement in food purchasing behavior. European Journal of Marketing. 2007: 41(7/8): 888-914.

[10] Petty, R.E., Cacioppo, J.T. Communication and persuasion: Central and peripheral routes to attitude change. New York: Springer-Verlag; 1986.

[11] Cabañero, C.P. La implicación del consumidor en la adquisición de bienes y servicios. EsicMarket. 2006; 123: 93-113.

[12] Viejo-Fernández, N., Sanzo-Pérez, M.J., Vázquez-Casielles, R. Different kinds of research shoppers, different cognitive-affective consequences. Spanish Journal of Marketing-ESIC. 2019; 23(1): 45-68.

[13] Viejo-Fernández, N., \& Sanzo-Pérez, M. J. Combining internal and external drivers to understand omni-channel behavior. International Journal of Business Marketing and Management. 2020; 5(11).

[14] Mckinsey (2019). The State of Fashion 2020. Available at: https://www.mckinsey.com/industries/retail/our-insights/the-state-of-fashion-2020-navigatinguncertainty.

[15] PwC (2018). Rethinking retail: The role of the physical store. Available at: https://www.pwc.be/en/documents/20180627-rethinking-retail.pdf.

[16] Mosquera, A., Olarte-Pascual, C., Juaneda-Ayensa, E., Sierra Murillo, Y. The role of technology in an omnichannel physical store: Assessing the moderating effect of gender. Spanish Journal of Marketing. 2018; 22(1), 63-82.

[17] Solomon, M.R. Comportamiento del consumidor, New Jersey: Prentice Hall; 1997.

[18] Pookulangara, S., Hawley, J., Xiao, G. Explaining multichannel consumer's channel-migration intention using theory of reasoned action. International Journal of Retail \& Distribution Management. 2011; 39(3), 183-202.

[19] Rapp, A., Bakera, T.L., Bachrachb, D.G., Ogilviea, J., Beitelspacherc, L.S. Perceived customer showrooming behavior and the effect on retail salesperson self-efficacy and performance. Journal of Retailing. 2015; 91(2): 358-369.

[20] Yurova, Y., Rippé, C.B., Weisfeld-Spolter, S., Sussan, F., Arndt, A. Not all adaptive selling to omniconsumers is influential: The moderating effect of product type. Journal of Retailing and Consumer Services. 2016: 34, 271-277.

[21] Bezes, C. Identifying central and peripheral dimensions of store and website image: Applying the elaboration likelihood model to multichannel retailing. Journal of Applied Business Research. 2015; 31(4): 14-53.

[22] Gensler, S., Neslin, S.A.,Verhoef, P. C. The showrooming phenomenon: it's more than just about price. Journal of Interactive Marketing. 2017; 38: 29-43.

[23] FashionUnited (2020). Global fashion industry statistics-International apparel. Available at: https://fashionunited.com/global-fashion-industry-statistics/.

[24] López-López, I., Salvador Ruiz-de-Maya, S. Warlop, L. When sharing consumption emotions with strangers is more satisfying than sharing them with friends. Journal of Service Research. 2014; 17(4): $475-488$.

[25] Viejo-Fernández, N., Sanzo-Pérez, M.J., Vázquez-Casielles, R. Is showrooming really so terrible? Start understanding showroomers. Journal of Retailing and Consumer Services. 2020; 54: 102048.

[26] Gil, J. (2017). Competencias clave del Vendedor 4.0. Available at: https://es.linkedin.com/pulse/competencias-clave-del-vendedor-40-jos $\% \mathrm{C} 3 \% \mathrm{~A} 9$-gil. 